\title{
A Causal Approach to Interrelated Family Events: A Cross-national Comparison of Cohabitation, Nonmarital Conception, and Marriage
}

\author{
Hans-Peter Blossfeld \\ Melinda Mills \\ Faculty of Sociology \\ University of Bielefeld \\ Bielefeld, Germany
}

\begin{abstract}
:
One of the most important advances brought about by life course and event history studies is the use of parallel or interdependent processes as explaining factors in transition rate models. The purpose of this paper is to demonstrate a causal approach to the study of interrelated family events. Various types of interdependent processes are described first, followed by two event history perspectives: the 'system' and 'causal' approach. The authors assert that the causal approach is more appropriate from an analytical point of view as it provides a straightforward solution to simultaneity, cause-effect lags, and temporal shapes of effects. Based on comparative cross-national applications in West and East Germany, Canada, Latvia, and the Netherlands, we demonstrate the usefulness of the causal approach by analyzing two highly interdependent family processes: entry into marriage (for individuals who are in a consensual union) as the dependent process and first pregnancy/childbirth as the explaining one. Both statistical and theoretical explanations are explored emphasizing the need for conceptual reasoning.
\end{abstract}


Empirical Research and Applications - Hans-Peter Blossfeld and Melinda Mills

\section{Résumé}

L'utilisation des processus interdépendants ou parallèles en tant que facteurs explicatifs dans des modèles des transitions aux quotients instantanés est une des contributions les plus importantes de l'analyse des biographies. Le but de cet article est d'appliquer une approche causale à l'analyse des événements familiaux interdépendants. L'étude présente une typologie de processus parallèles et deux perspectives de l'analyse des biographies: les approches 'systémique' et 'causale'. Les auteurs soutiennent que l'approche causale est plus appropriée du point de vue d'analyse. Elle offre une solution valable aux problèmes de simultanéité, les problèmes de décalage dans les intervalles entre la cause et l'effet, et, enfin, les problèmes des courbes temporelles modelées par les effets. L'utilité de cette approche causale est démontrée grâce à l'analyse de deux processus fortement interdépendants: la transition des unions consensuelles au mariage, en tant que variable dépendante, et la première grossesse/naissance en tant que variable explicative. Cette analyse est appliquée dans plusieurs pays : l'Allemagne de l'Est et de l'Ouest, le Canada, la Lettonie, et le Pays-Bas. Tant l'interprétation statistique que celle théorétique sont explorées afin de souligner le besoin d'un raisonnement conceptuel.

Key words: Interdependent processes, causal analysis, event history analysis, longitudinal data, cross-national comparisons, fertility, nuptiality

\section{Introduction}

The study of parallel, coupled, or interdependent processes as explaining factors in transition rate models is one of the most important advances in life course studies and event history analysis (Willekens, 1991; Courgeau and Lelièvre, 1992; Blossfeld and Rohwer, 1995). The purpose of this paper is to demonstrate the usefulness of a causal approach to interdependent family events based on cross-national empirical investigations from five countries. We first describe different types of parallel processes and time-dependent covariates, the latter being often used to include the sample path of parallel processes in transition rate models. Second, the widely used 'system approach' to interdependent processes is described, in addition to its limitations. Third, a 'causal approach' to interdependent systems is proposed which we assert is more appropriate for an analysis of coupled processes from an analytical point of view. In particular, it provides a straightforward solution to: (1) the simultaneity problem of interdependent processes, (2) the identification of lags between causes and their effects; and, (3) the study of temporal shapes of effects. Based on separate applications with the data available from West and East Germany, Canada, 
A Causal Approach to Interrelated Family Events: A Cross-national Comparison of Cohabitation, Nonmarital Conception and Marriage

Latvia, and the Netherlands, the usefulness of the causal approach is demonstrated by analyzing two highly interdependent family processes: entry into marriage (for individuals in a consensual union) as the dependent process and first pregnancy/childbirth as the explaining one. After describing potential statistical reasons for the time-dependent effects, we move to more substantive explanations, including the importance of actors, probabilistic causal relations, preferences and negotiation, observed and unobserved decisions and the problem of conditioning on future events.

\section{Parallel and Interdependent Processes}

Parallel or interdependent processes can operate at various levels. For example:

1. There can be parallel processes at the level of the individual in different domains of life. For instance, one may ask how upward and downward moves in an individual's job career influences her/his family trajectory (e.g., Blossfeld and Huinink, 1991; Blossfeld, 1995).

2. There may be parallel processes at the level of individuals interacting with each other, termed 'interdependent or linked lives' (Elder, 1987). One might study the effect of the career of the husband on his wife's labour force participation (Bernasco, 1994; Blossfeld and Drobni(5), forthcoming) or how the death or migration of the head of the household impacts other family members (Young, 1992).

3. There may be parallel processes at the intermediate level such as how the changing household structure determines women's labour force participation (Blossfeld and Hakim, 1997).

4. There may be parallel processes at the macro level. Here the researcher may be interested, for instance, in the effect of changes in the business cycle on family formation (e.g., Easterlin, 1976; Blossfeld and Huinink, 1991).

5. Finally, there may be any combination of the aforementioned processes of type 1 to 4 . For example, in life course studies, cohort and period effects, in addition to time-dependent covariates at different levels must be included simultaneously (Blossfeld, 1986; Mayer and Huinink, 1990). Such an analysis combines processes at the individual level (life course change) with two kinds of processes at the macro level: (a) variations in structural conditions across successive (birth, marriage, etc.) cohorts; and, (b) changes in particular historical conditions affecting all cohorts in the same way. 
In event history analysis, time-dependent covariates are often used to include the sample path of parallel processes in transition rate models. In the literature, however, only two types of time-dependent covariates have been described as not being subject to reverse causation (see for e.g., Kalbfleisch and Prentice, 1980; Tuma and Hannan, 1984; Blossfeld, Hamerle and Mayer, 1989; Yamaguchi, 1991; Courgeau and Lelièvre, 1992).

The first are defined time-dependent covariates whose total time path (or functional form of change over time) is determined in advance in the same way for all subjects under study. For example, process time like age or duration in a state (e.g., duration of marriage in divorce studies), is a defined time-dependent covariate because its values are predetermined for all subjects. It is the predefined onset of the process when the individual becomes 'at risk' in the event history model. Thus, by definition, the values of these time-dependent covariates cannot be affected by the dependent process under study.

The second type is ancillary time-dependent covariates whose time path is the output of a stochastic process that is external to the units under study. Again, by definition, the values of these time-dependent covariates are not influenced by the dependent process itself. Examples of time-dependent covariates that can be considered external in the analysis of individual life courses are those that reflect changes at the macro level of society (e.g., unemployment rates, occupational structure) or at the population level (e.g., composition of the population in terms of age, sex, race, etc.), provided the contribution of each unit is small and does not really affect the structure in the population (Yamaguchi, 1991).

In contrast to defined or ancillary time-dependent covariates are internal timedependent covariates, which are often referred to as being problematic for causal analysis in event history models (e.g., Kalbfleisch and Prentice, 1980; Tuma and Hannan, 1984; Blossfeld, Hamerle, and Mayer, 1989; Yamaguchi, 1991; Courgeau and Lelièvre, 1992). An internal time-dependent covariate $\mathrm{Y}_{t}^{B}$ describes a stochastic process, considered in a causal model as being the cause, that in turn is affected by another stochastic process $\mathrm{Y}_{t}^{A}$, considered in the causal model as being the effect. Thus, there are direct effects in which the processes autonomously affect each other $\left(\mathrm{Y}_{t}^{B}\right.$ affects $\mathrm{Y}_{t}^{A}$ and $\mathrm{Y}_{t}^{A}$ affects $\left.\mathrm{Y}_{t}^{B}\right)$, and there are 'feedback' effects, in which these processes are affected by themselves via the respective other processes $\left(\mathrm{Y}_{t}^{B}\right.$ affects $\mathrm{Y}_{t}^{B}$ via $\mathrm{Y}_{t}^{A}$ and $\mathrm{Y}_{t}^{A}$ affects $\mathrm{Y}_{t}^{A}$ via $\mathrm{Y}_{t}^{B}$ ). In other words, such processes are interdependent and form what has been called a dynamic system (Tuma and Hannan, 1984). Interdependence is typical at the individual level for processes in different domains of life and at the level of a few individuals interacting with each other (e.g., career trajectories of partners) (see Blossfeld and Drobnic, forthcoming). For example, the empirical literature 
A Causal Approach to Interrelated Family Events: A Cross-national Comparison of Cohabitation, Nonmarital Conception and Marriage

suggests that the employment trajectory of an individual is influenced by his/her marital history and marital history is dependent on the employment trajectory. In the literature, there are two central approaches to modelling parallel processes, what we term here as the 'system approach' and the 'causal approach,' with the former often used to deal with such dynamic systems.

\section{Interdependent Processes: The System Approach}

The system approach in the analysis of interdependent processes (Tuma and Hannan, 1984; Courgeau and Lelièvre, 1992) defines change in the system of interdependent processes as a new 'dependent variable.' Thus, instead of analyzing one of the interdependent processes with respect to its dependence on the respective others, the focus is on the modelling of a system of state variables. In other words, the interdependence between the various processes is taken into account only implicitly.

Suppose that there are $\mathrm{J}$ interrelated qualitative time-dependent variables (i.e., processes): $\mathrm{Y}_{t}^{A}, \mathrm{Y}_{t}^{B}, \mathrm{Y}_{t}^{C}, \ldots, \mathrm{Y}_{t}^{J}$. A new time-dependent variable (process) $\mathrm{Y}_{t}$, representing the system of these $\mathrm{J}$ variables, is then defined by associating each discrete state of the ordered J-tuple with a particular discrete state of $\mathrm{Y}_{t}$. As shown by Tuma and Hannan (1984), as long as change in the entire system only depends on the various states of the $\mathrm{J}$ qualitative variables and on exogenous variables, this model is identical to modelling change in a single qualitative variable. ${ }^{1}$ Thus, the idea of this approach is to simply define a new joint state space, based on the various states spaces of the coupled qualitative processes, and then to proceed as in the case of a single dependent process.

Although the system approach provides interesting insights into the behaviour of the dynamic system as a whole, it has several disadvantages. First, from a causal analytical point of view, the approach presented by Courgeau and Lelièvre (1992) does not provide direct estimates of effects of coupled processes on the process under study. In other words, when using the system approach, one normally does not know to what extent one or more of other coupled processes affect the process of interest, controlling for other exogenous variables and the history of the dependent process. Since the effects can only be identified in simple models via a comparison of the constant terms of hazard rate equations, it is only possible to compare transition rates for general models without covariates (see Courgeau and Lelièvre, 1992; Blossfeld and Rohwer, 1995). ${ }^{2}$ Second, in particular, a mixture of qualitative and quantitative processes, in which the transition rate of a qualitative process depends on the levels of one or more metric variables, turns out to be a problem in this approach. Tuma and Hannan (1984) suggest that in these situations it is not very useful. Third, this approach is also unable to handle interdependencies between coupled processes occurring in specific phases of the process, for example, in the life course or when 
interdependencies are dynamic over time and might be reversed in later life phases (see Courgeau and Lelièvre, 1992). Tuma and Hannan (1984) call this 'cross-state dependence.' Finally, the number of origin and destination states of the combined process $\mathrm{Y}_{t}$, representing the system of $\mathrm{J}$ variables, may lead to practical problems. Even when the number of variables and their distinct values are small, the state space of the system is large. Therefore, in light of increasing number of parameters, the event history data sets must contain a great number of events, even if only the most general models of change (i.e., models without covariates) are to be estimated.

In summary, the system approach has many limitations for analyzing interdependent processes. We therefore suggest a different perspective in modelling dynamic systems, which we call the 'causal approach.'

\section{Interdependent Processes: The Causal Approach}

The underlying idea of the causal approach for analyzing interdependent processes can be outlined as follows (Blossfeld and Rohwer, 1995). Based on theoretical reasons, the researcher focuses on one of the interdependent processes and considers it as the dependent one. The future changes of this process are linked to the present state and history of the entire dynamic system as well as to other exogenous variables (see Blossfeld, 1986; Gardner and Griffin, 1986; Blossfeld and Huinink, 1991). Thus, in this approach the variable $\mathrm{Y}_{t}$, representing the system of joint processes at time $t$, is not used as a multivariate dependent variable. Instead, the history and the present state of the system are seen as a condition for change in (any) one of its processes. The question of how to give a more precise formulation for the causal approach remains. The following ideas may be helpful.

\section{Causes and Time-dependent Covariates}

In an influential paper, Holland (1986) developed the idea that causal statements imply counterfactual reasoning: If the cause had been different, there would have been another outcome, at least with a certain probability. However, the consequences of conditions that could be different from their actual state are obviously not empirically observable. This means that it is simply impossible to observe the effect that would have happened on the same unit of analysis, if it were exposed to another condition at the same time.

To find an empirical approach to examine longitudinal causal relations, Blossfeld and Rohwer (1995) suggested the examination of conditions that actually do change in time. These changes are characterized as events or transitions. More formally, an event is specified as a change in a variable, and this change must happen at a specific point in time. The most obvious empirical representation of 
A Causal Approach to Interrelated Family Events: A Cross-national Comparison of Cohabitation, Nonmarital Conception and Marriage

causes is therefore in terms of quantitative or qualitative variables that can change their states over time. This statement links very naturally to the concept of time-dependent covariates. The role of a time-dependent covariate in this approach is to indicate that a (qualitative or metric) causal factor has changed its state at a specific time and that the unit under study is exposed to another causal condition. From this point of view, it seems somewhat misleading to regard processes as causes. Rather, only events, or changes in state space can sensibly be viewed as possible causes.

\section{Time and Causal Effects}

Consequently, we do not suggest that process $\mathrm{Y}_{t}^{A}$ is a cause of process $\mathrm{Y}_{t}^{B}$, but that a change in $\mathrm{Y}_{t}^{A}$ could be a cause (or provide a new condition) of a change in $\mathrm{Y}_{t}^{B}$. Or, more formally:

$$
\Delta \mathrm{Y}_{t}^{A} \rightarrow \Delta \mathrm{Y}_{t^{\prime}}^{B} \quad \mathrm{t}<\mathrm{t}^{\prime}
$$

meaning that a change in variable $\mathrm{Y}_{t}^{A}$ at time $\mathrm{t}$ is a cause of a change in variable $\mathrm{Y}_{t^{\prime}}^{B}$ at a later point in time, $\mathrm{t}^{\prime}$. It is not implied, of course, that $\mathrm{Y}_{t}^{A}$ is the only cause that might affect $\mathrm{Y}_{t^{\prime}}^{B}$. So, we speak of causal conditions to stress that there might be, and normally is, a quite complex set of causes. (see Marini and Singer, 1988) Thus, if causal statements are studied empirically, they must intrinsically be related to time, which relates to three important aspects.

First, to speak of a change in variables necessarily implies reference to a time axis. We require at least two points in time to observe that a variable has changed its value. Of course, at least approximately, we can say that a variable has changed its value at a specific point in time. Therefore, we use the symbols to refer to changes in the values of the time-dependent variable $\Delta \mathrm{Y}_{t}^{A}$ and the state variable $\Delta \mathrm{Y}_{t}^{B}$ at time t. This leads to the important point that causal statements relate changes in two (or more) variables.

Second, we must consider time ordering, time intervals and apparent simultaneity. There is a time ordering between causes and effects. The cause must precede the effect in time: $\mathrm{t}<\mathrm{t}^{\prime}$, in the formal representation given above. This seems to be generally accepted (Eells, 1991: Ch. 5). As an implication, there must be a temporal interval between the change in the variable representing a cause, and the change in the variable representing a corresponding effect. Thus, the role of time in causal explanations does not only lie in specifying a temporal 
order in which the effect follows the cause in time but also implies that a temporal interval is necessary for the cause to have an impact. (Kelly and McGrath, 1988) It takes a finite amount of time for the cause to produce the effect. The time interval may be very short or very long, but can never be zero or infinity (Kelly and McGrath, 1988). In other words, there can never be simultaneity of cause and its effect.

In this respect, our causal approach to the analysis of interdependent systems significantly differs from the approach by Lillard (1993), Lillard and Waite (1993), Lillard, Brien and Waite (1995), and Brien, Lillard and Waite (1999). They estimate the hazard rate of a dependent process as a function of: (1) the actual current state of an independent process as well as (2) its simultaneous (unobserved) hazard rate.

Some effects take place almost instantaneously. For example, if the effect occurs at microsecond intervals, then the process must be observed in these small time units to uncover causal relations. However, some effects may occur in a time interval too small to be measured by any given methods, so that cause and effect seem to occur at the same point in time. Apparent simultaneity is often the case in those social science applications where basic observation intervals are relatively crude such as, for example, yearly data about first marriage and first childbirth (Blossfeld, Manting, and Rohwer, 1993). For these parallel processes, the events 'first marriage' and 'first childbirth' may be functionally interdependent, but whether these two events are observed simultaneously or successively depends on the degree of temporal refinement of the scale used in making the observations. Other effects need a long time until they start to occur. Marini and Singer (1988), for example, discuss the gap between mental causal priority and observed temporal sequences of behaviour. Thus, there is a delay or lag between cause and effect that must be specified in an appropriate causal analysis. Unfortunately, in most of the current demographic theories and interpretations of research findings, this interval is left unspecified.

This leads to the third point regarding the temporal shapes of the unfolding effect. In addition to the question of how long the delay between the timing of the cause and the beginning of the unfolding effect is, there might be different shapes of how the causal effect $\mathrm{Y}_{t}$, unfolds over time. While the problem of time-lags is widely recognized in the demographic and social science literature, almost no attention has been given to the temporal shapes of effects (Kelly and McGrath, 1988). Researchers often seem to either ignore or be ignorant about the fact that causal effects could be highly time-dependent as well. Figure 1 illustrates several possible shapes these effects may trace over time. In Figure 1a, there is an almost all-at-once change that is then maintained. In Figure 1b, the effect occurs with some lengthy time-lag and is then time-invariant. In Figure 1c, the effect starts almost immediately and then gradually increases whereas in Figure 1d, there is an almost all-at-once increase which reaches a maximum after some time and then decreases. Finally, in Figure 1e, a cyclical effect pattern over time is 
A Causal Approach to Interrelated Family Events: A Cross-national

Comparison of Cohabitation, Nonmarital Conception and Marriage

described. Thus, an appropriate understanding of causal relations between variables should take into account that the causal relationship itself may change over time. This seems particularly important in demographic applications of causal reasoning. In these applications, we generally cannot rely on the assumption of eternal, time-less laws but have to recognize that the causal mechanisms may change during the development of social processes. In fact, analysis of these changes of mechanisms is usually what is of particular interest in demography.

\section{The Principle of Conditional Independence}

We consider here only interdependent processes that are not just an expression of another underlying process so that it is meaningful to assess the properties of the two processes without regarding the underlying one. This means, for instance, that what happens next to $\mathrm{Y}_{t}^{A}$ should not be directly related to what happens to $\mathrm{Y}_{t}^{B}$ at the same point in time, and vice versa. This condition, which we call 'local autonomy' (see Pötter and Blossfeld, forthcoming), can be formulated in terms of the uncorrelatedness of the prediction errors of both processes, $\mathrm{Y}_{t}^{A}$ and $\mathrm{Y}_{t}^{B}$, and excludes stochastic processes that are functionally related.

Combining the ideas to this point, a causal view on parallel and interdependent processes becomes easy, at least in principle. Given two parallel processes, $\mathrm{Y}_{t}^{A}$ and $\mathrm{Y}_{t}^{B}$, a change in $\mathrm{Y}_{t}^{A}$ at any (specific) point in time $\mathrm{t}^{\prime}$ may depend on the history of both processes up to, but not including $\mathrm{t}^{\prime}$. Or stated in another way: what happens with $\mathrm{Y}_{t}^{A}$ at any point in time $\mathrm{t}^{\prime}$ is conditionally independent of what happens with $\mathrm{Y}_{t}^{B}$ at $\mathrm{t}^{\prime}$, conditional on the history of the joint process $\mathrm{Y}_{t}=$ $\left(\mathrm{Y}_{t}^{A}, \mathrm{Y}_{t}^{B}\right)$ up to, but not including, $\mathrm{t}^{\prime}$. Of course, the same reasoning can be applied if one focuses on $\mathrm{Y}_{t}^{A}$ instead of $\mathrm{Y}_{t}^{B}$ as the 'dependent variable.' This is the principle of conditional independence for parallel and interdependent processes. 
Figure 1

Different Temporal Shapes of How a Change in Variable $x$, Occurring at Point in Time $\mathrm{t}_{x}$, Results in a Change in Variable $y$
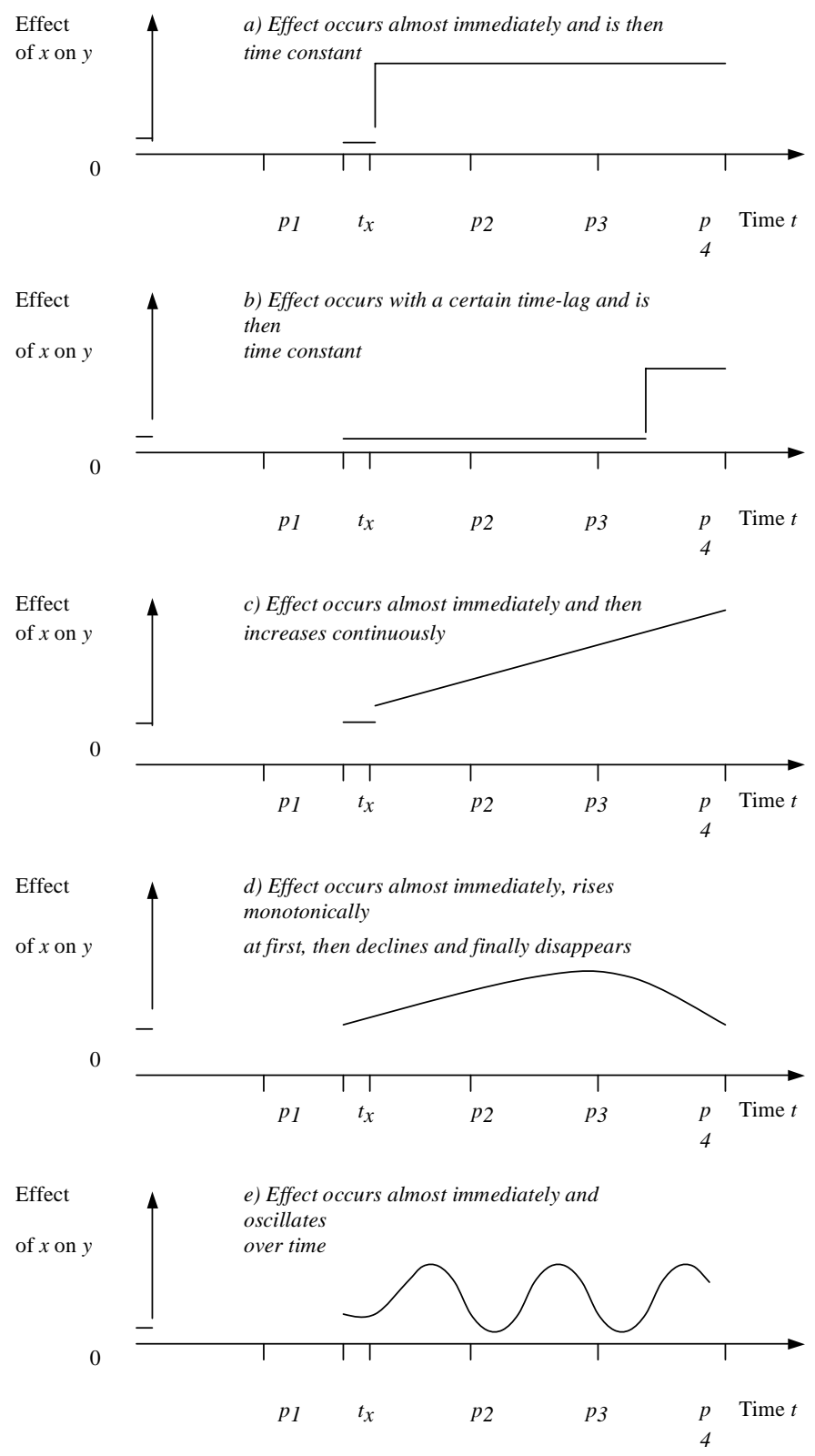
The same idea can be developed more formally. Beginning with a transition rate model for the joint process, $\mathrm{Y}_{t}=\left(\mathrm{Y}_{t}^{A}, \mathrm{Y}_{t}^{B}\right)$, and assuming the principle of conditional independence, the likelihood for this model can be factorized into a product of the likelihoods for two separate models: a transition rate model for $\mathrm{Y}_{t}^{A}$ which is dependent on $\mathrm{Y}_{t}^{B}$ as a time-dependent covariate, and a transition rate model for $\mathrm{Y}_{t}^{B}$ which is dependent on $\mathrm{Y}_{t}^{A}$ as a time-dependent covariate. Estimating the effects of time-dependent (qualitative and metric) processes on the transition rate can be easily achieved by applying the method of episode-splitting (Blossfeld, Hamerle, and Mayer, 1989; Blossfeld and Rohwer, 1995). ${ }^{3}$

This result has an important implication for the modelling of event histories. From a technical point of view there is no need to distinguish between defined, ancillary, and internal covariates because all of these time-dependent covariate types can be treated equally in the estimation procedure. A distinction between defined and ancillary covariates on the one hand and internal covariates on the other is, however, sensible from a theoretical perspective, because only in the case of internal covariates does it make sense to examine whether parallel processes are independent, whether one of the parallel processes is endogenous and the other ones are exogenous, or whether parallel processes form an interdependent system (i.e., they are all endogenous). We will now present a series of empirical applications that illustrate the viability of the causal approach.

\section{Application Examples: The Effect of First Pregnancy/First Birth on Entry into First Marriage for Couples Living in Consensual Unions}

In order to demonstrate the utility of the causal approach to interdependent processes, we report the results of three cross-national comparative studies about the effect of first pregnancy/first birth on entry into first marriage for couples living in consensual unions. The earliest investigation was conducted by Blossfeld, Manting and Rohwer (1993), followed by Blossfeld, Klijzing, Pohl and Rohwer (1996; 1999) and finally, Mills and Trovato (forthcoming 2001).

The basic research problem underpinning these studies can be defined as follows. Historically, marriage has - as a rule - preceded the birth of a child in many countries. However, in the last two decades, the link between marriage and childbirth has become more complex, a phenomenon that has occurred in conjunction with a rapid rise in consensual unions. The three studies explored this complex relationship by examining how the experience of a pregnancy within a consensual union conditioned the likelihood of transition to a formal marriage with the same partner. In the later investigations, the process was modelled as explicitly time-dependent, with entry into first marriage as the 
dependent and first pregnancy/childbirth as the explaining process. The theoretical framework used to provide a substantive explanation of the timedependent process, is the rational actor model which proposes that norm-guided and rational self-centered behaviour co-exist (Blossfeld and Prein, 1998; Blossfeld et al., 1999; Mills and Trovato, forthcoming 2001). Thus, when a common-law couple's preferences regarding marriage are vague and diffuse, the discovery of a pregnancy engenders a highly time-dependent process of preference formation and persuasion.

\section{The Blossfeld-Manting-Rohwer Study}

The purpose of the earlier study by Blossfeld, Manting, and Rohwer (1993) was to gain insight into the process of how consensual unions were transformed into marriages in the former West Germany and the Netherlands. The study focussed on the effect of fertility on the rate of entry into marriage, controlling for other important covariates in a transition rate model.

In order to study these complex relationships, nationally representative longitudinal data were used from the German Socioeconomic Panel for the former West Germany and the Netherlands Fertility Survey. Both data sets provide information about the dynamics of consensual unions in the 1980s. In both countries, attention was limited to members of the cohorts born between 1950-1969 who started a consensual union between 1984-1989 in the former West Germany and between 1980-1988 in the Netherlands.

Given the interdependent processes of first marriage and first pregnancy/first birth, a change in the marriage process at any point in time during a consensual union may depend on the history of both processes up to, but not including $t^{\prime}{ }^{4}$ Thus, a change in the marriage process at time $t^{\prime}$ is conditionally independent of what happens with the fertility process at $\mathrm{t}^{\prime}$, conditional on the history of the joint process up to, but not including $\mathrm{t}^{\prime}$. As discussed previously, the likelihood for the joint process of first marriage and first birth can therefore be factorized into a product of the likelihoods for two separate models: (1) a transition rate model for first pregnancy/first birth which is dependent on first marriage as a timedependent covariate, and (2) a transition rate model for first marriage which is dependent on first pregnancy/first birth as a time-dependent covariate.

We will discuss the results of the latter transition model, which utilized a piecewise constant exponential model to estimate transitions from consensual unions to both marriage and dissolution. Within this, we address only the fertility effects and the transition to marriage. The change in the fertility process was included in the transition rate model as a series of time-dependent dummy variables with the following states: 'not pregnant,' 'pregnant,' 'first childbirth,' and ' 6 months after birth.' As shown in Table 1, the effects of the fertility 
Table 1

Piecewise Constant Exponential Model of the Transitions from Consensual Unions to Marriage and Dissolution for the Federal Republic of Germany (West Germany) and the Netherlands

\begin{tabular}{|c|c|c|c|c|}
\hline \multirow{2}{*}{ Covariates } & \multicolumn{2}{|c|}{ Entry into Marriage } & \multicolumn{2}{|c|}{ Dissolution of Consensual Unions } \\
\hline & $\begin{array}{c}\text { Federal Republic of } \\
\text { Germany (3) }\end{array}$ & Netherlands (4) & $\begin{array}{c}\text { Federal Republic of } \\
\text { Germany (3) }\end{array}$ & Netherlands (4) \\
\hline Constant & $-2.79 * *$ & $-4.01 * *$ & $-10.6 * *$ & $-4.92 * *$ \\
\hline \multicolumn{5}{|l|}{ Duration } \\
\hline Until 2 years & 0.08 & -0.01 & $-0.49 * *$ & $-0.18 * *$ \\
\hline More than 2 years & -0.08 & 0.01 & $0.49 * *$ & $0.18 * *$ \\
\hline \multicolumn{5}{|l|}{ Birth cohort } \\
\hline $1950-53(1)$ & -0.09 & 0.07 & 0.37 & -0.19 \\
\hline $1954-58$ & 0.01 & $0.16 *$ & 0.22 & -0.13 \\
\hline $1959-63$ & 0.11 & 0.00 & $-0.68 *$ & -0.15 \\
\hline $1964-69$ (2) & -0.03 & $-0.23 * *$ & -0.09 & $0.46 * *$ \\
\hline \multicolumn{5}{|l|}{ School enrollment } \\
\hline At school & $-0.16 *$ & $-0.36 * *$ & -0.4 & 0.11 \\
\hline Not at school & $0.16 *$ & $0.36 * *$ & 0.4 & -0.11 \\
\hline \multicolumn{5}{|l|}{ Educational level } \\
\hline low & $-0.17 *$ & $0.14 *$ & 0.03 & -0.08 \\
\hline medium & -0.09 & -0.07 & 0.29 & 0.1 \\
\hline high & 0.26 & -0.07 & -0.32 & -0.03 \\
\hline \multicolumn{5}{|l|}{ Fertility } \\
\hline not pregnant & $-1.19 * *$ & $-0.43 * *$ & $5.48 * *$ & -0.09 \\
\hline pregnant & $1.13 * *$ & $1.19 * *$ & -5.45 & 0.17 \\
\hline first child birth & $1.21 * *$ & 0.21 & -4.75 & -0.69 \\
\hline 6 months after birth & $-1.15 * *$ & $-0.98 * *$ & $4.72 *$ & $0.61 *$ \\
\hline \multicolumn{5}{|l|}{ Sex } \\
\hline men & -0.08 & - & 0.09 & - \\
\hline women & 0.08 & - & -0.09 & - \\
\hline \multicolumn{5}{|l|}{ Married before } \\
\hline no & 0.07 & - & -0.01 & - \\
\hline yes & -0.07 & - & 0.01 & - \\
\hline
\end{tabular}

$*$ = significant at the 0.01 level; ** = signficant at the 0.05 level.

Notes: (1) For West Germany the birth cohort of 1949 was also included.

(2) For West Germany the birth cohort for 1969 was not included.

(3) Men and women

(4) Only women. 
dummy variables on the marriage rate were significant for both countries and worked in the same direction. As long as women were not pregnant, a significant and comparatively low rate of entry into marriage for those living in a consensual union is observed. But, as soon as a woman became pregnant (in West Germany also around the time when the woman gave birth to her child), the rate of entry into marriage increases strongly. If the couple did not get married within six months after the child was born, the rate of entry into marriage again dropped to a comparatively low level in West Germany. In the Netherlands, this level is even below the 'not pregnant' level (see Manting, 1994).

\section{The Blossfeld-Klijzing-Pohl-Rohwer Study}

About a year after this comparative study was conducted, Blossfeld et al. (1996; 1999) wanted to examine whether these results could be replicated with new data from the German Fertility and Family Survey. These data were collected retrospectively from respondents aged 20-39 years in West and East Germany in 1992 (see Pohl, 1995). They started with a simple model and conducted a preliminary analysis of the process of entry into first marriage for couples living in consensual unions using only one time-dependent dummy variable for the event of first birth. However, the effect of this covariate was, surprisingly, not significant. This 'finding,' of course, created a lot of confusion in the research group. What happened to the fertility effect? After much theoretical discussion, a hypothesis was put forward that could explain the seemingly contradictory results of the estimated models: the effect of changes in fertility on entry into marriage must be strongly time-dependent in a very specific way. According to the first study, the rate is low as long as women are not pregnant, then starts to rise at some time shortly after conception, increases during pregnancy to a maximum and finally drops again a few months after birth has taken place. But, when a time-dependent covariate is switched at the time of childbirth, it confounds a period with a low marriage rate (up to the time of discovery of conception) with a period with a high marriage rate (during pregnancy) and compares with a relatively low rate (during the period after birth). The aggregated average tendency to marry before the child is born could equal the aggregate average tendency to marry after the child is born, and thus make the estimated coefficient of the time-dependent covariate 'childbirth' not significantly different from zero.

To deal with this problem, a series of 14 time-dependent pregnancy/birth binary variables were created using information from the reported date of first birth (see Table 2). These variables were grouped into categories which ranged from 'marriage before the month of pregnancy,' 'month of the pregnancy,' 'one month since pregnancy,' and so on, to 'more than seven months after birth' (for a tabular and graphical depiction refer to Mills, 2000: 101-2). To be clear, since we did not have information on the timing of pregnancy, but only on the timing of successful births, we were looking backward in time from the first birth and thus estimated the date of pregnancy as nine months before the date of birth. As we discuss in 
A Causal Approach to Interrelated Family Events: A Cross-national Comparison of Cohabitation, Nonmarital Conception and Marriage

greater detail shortly, this presents two potential problems: neglecting abortions and miscarriages, and conditioning past on future events. We will return to a more substantive and non-statistical explanation of these results and implications of our decisions following the description of the third study.

\section{The Mills-Trovato Study}

Building on the previous two studies, Mills and Trovato (forthcoming 2001) replicated the study by Blossfeld and colleagues (1999) to see if the findings would hold in other diverse contexts such as North America or Eastern Europe or in later surveys collected within Western Europe. ${ }^{5}$ For this reason, we selected Canada and Latvia and more recent data from the Netherlands for the analysis. Replication using diverse contexts provides a more useful validation than statistical testing of many models on only one data set. Normally, there is less chance of an artefact, more kinds of variation can be explored, and alternative explanations can be ruled out (Freedman, 1991). A further impetus for this study centered on the fact that consensual unions and non-marital births in Eastern Europe and the Baltic States have skyrocketed since the 1980s (Katus, 1992). Yet, Eastern European countries are rarely included in comparative analyses. Also, it would be of interest to see whether this type of behaviour would hold in the North American context in a country such as Canada. Using data from the Fertility and Family Surveys (FFS) for Canada (1995), ${ }^{6}$ Latvia (1995) and the Netherlands (1993), we selected a comparative sample of women born between 1950 and 1969.

Table 2 summarizes the results of the partial likelihood estimates from the Cox models for the transition from consensual union to marriage for the final model (of 5 models) from the Blossfeld et al. (1999) and Mills and Trovato (forthcoming 2001) studies. Figure 2 plots the final partial likelihood estimates (coefficients) for the time-dependent pregnancy/birth process variable. Overall, the findings suggest a high degree of uniformity, though the levels and significance of effects tend to vary slightly across countries. Notwithstanding these similarities, we acknowledge that the Canadian and East German data show a few unexpected effects on the transition rate. In Canada, the likelihood appears to drop earlier, at approximately three months before birth, with fluctuations after that point. We attribute this largely to methodological factors such as that some of the monthly temporal data had to be partially estimated as they are not released for confidentiality reasons. ${ }^{7}$ In East Germany, there is large drop one month before birth as opposed to the month of birth. Difference in the significance level of results by country (especially Canada and East Germany) may also be related to smaller sample sizes and fewer events. The theoretical reasons behind the generally comparable effects that we observe across the five areas are central to understanding these investigations. 
Table 2

Partial Likelihood Estimates of the Transition

from Consensual Union to Marriage (Final Model) for West and East Germany, Canada, Latvia and the Netherlands

\begin{tabular}{|c|c|c|c|c|c|}
\hline \multirow[b]{2}{*}{ Covariates } & \multicolumn{5}{|c|}{ Final Model Results by Country } \\
\hline & $\begin{array}{c}\text { West } \\
\text { Germany }\end{array}$ & East Germany & Canada & Latvia & Netherlands \\
\hline \multicolumn{6}{|l|}{ Pregnancy/Birth Process } \\
\hline \multicolumn{6}{|l|}{ Time-dependent (1) } \\
\hline [time before pregnancy] & -1.2595 & -0.6179 & -1.0768 & -1.3918 & -1.0909 \\
\hline month of pregnancy & 0.1131 & 0.1729 & -0.1157 & 0.3822 & -0.2217 \\
\hline 1 month since pregnancy & 0.4783 & 0.2715 & 0.7107 & 0.2009 & 0.3769 \\
\hline 2 months since pregnancy & $0.8837 *$ & 0.4225 & $1.0851 *$ & $1.0109 *$ & $0.9374 *$ \\
\hline 3 months since pregnancy & $1.026 *$ & $0.7723 *$ & 0.5849 & $1.2959 *$ & $1.3229 *$ \\
\hline 4 months since pregnancy & $0.8578 *$ & $1.3903 *$ & 0.6563 & $1.0817 *$ & $1.5587 *$ \\
\hline 5 months since pregnancy & $0.9905 *$ & $0.7938 *$ & 0.248 & $0.9328 *$ & $1.0743 *$ \\
\hline 6 months since pregnancy & $0.8701 *$ & 0.151 & -0.8948 & $0.7525 *$ & 0.0227 \\
\hline 7 months since pregnancy & $0.8158 *$ & -0.5166 & -0.0365 & 0.4793 & 0.1028 \\
\hline 8 months since pregnancy & $-0.8121 *$ & $-2.5449 *$ & -0.5693 & -0.4727 & -0.235 \\
\hline Month of birth & -1.4709 & -0.6254 & -0.1115 & -1.6669 & -1.2711 \\
\hline 1-3 months after birth & -0.7513 & 0.2875 & 0.0096 & -0.0136 & -0.4595 \\
\hline 4-6 months after birth & -0.7638 & 0.1351 & 0.0363 & $-1.3576 *$ & -0.4404 \\
\hline $\begin{array}{l}\text { More than } 7 \text { months } \\
\text { after birth }\end{array}$ & $-0.9877 *$ & -0.0921 & $-0.5263 *$ & $-1.2336 *$ & $-1.6771 *$ \\
\hline \multicolumn{6}{|l|}{ Birth cohort (2) } \\
\hline $1965-69$ & -0.3094 & -0.6001 & $-0.4341 *$ & $-1.3096 *$ & $-2.2829 *$ \\
\hline $1960-64$ & -0.17 & -0.0536 & $-0.3589 *$ & $-0.8563 *$ & $-1.4258 *$ \\
\hline 1955-59 & -0.1486 & 0.092 & $-0.4324 *$ & -0.6154 & $-0.8228 *$ \\
\hline$[1950-54]$ & 0 & 0 & 0 & 0 & 0 \\
\hline \multicolumn{6}{|l|}{ Historical period } \\
\hline [Before 1974] & 0 & 0 & 0 & 0 & 0 \\
\hline $1974-83$ & 0.0882 & 0.3521 & -0.3027 & 0.001 & -0.2488 \\
\hline After 1983 & -0.1554 & 0.0363 & -0.2905 & -0.3164 & $-1.7642 *$ \\
\hline \multicolumn{6}{|l|}{ Highest education level } \\
\hline Low & $0.1722 *$ & -0.0189 & 0.1563 & -0.0164 & $0.249 *$ \\
\hline [Medium] & 0 & 0 & 0 & 0 & 0 \\
\hline High & -0.0354 & 0.0941 & -0.1092 & -0.0763 & $-0.1962 *$ \\
\hline \multicolumn{6}{|l|}{$\begin{array}{l}\text { Educational enrollment } \\
\text { Time-dependent }\end{array}$} \\
\hline In school & $-0.3575 *$ & 0.0061 & -0.3187 & 0.27 & -0.1856 \\
\hline [Out of school] & 0 & 0 & 0 & 0 & 0 \\
\hline
\end{tabular}

* = Significant at the 0.05 level. Results are shown for the final model 5.

Notes: (1) First covariate coded as centered effects, all others as cornered effects. Reference groups denoted by brackets. (2) Birth cohorts for West and East Germany are represented by 1968-72, 1963-67, 1958-62 and $1953=57$.

Source: Blossfeld et al. (1999) for West and East Germany and Mills and Trovato (forthcoming 2001) for Canada, Latvia and the Netherlands. 
Figure 2. Comparison of Parital Likelihood (Coefficients) of the Transition From Consensual Union to Marriage

West and East Germany, Canada, Latvia and the Netherlands

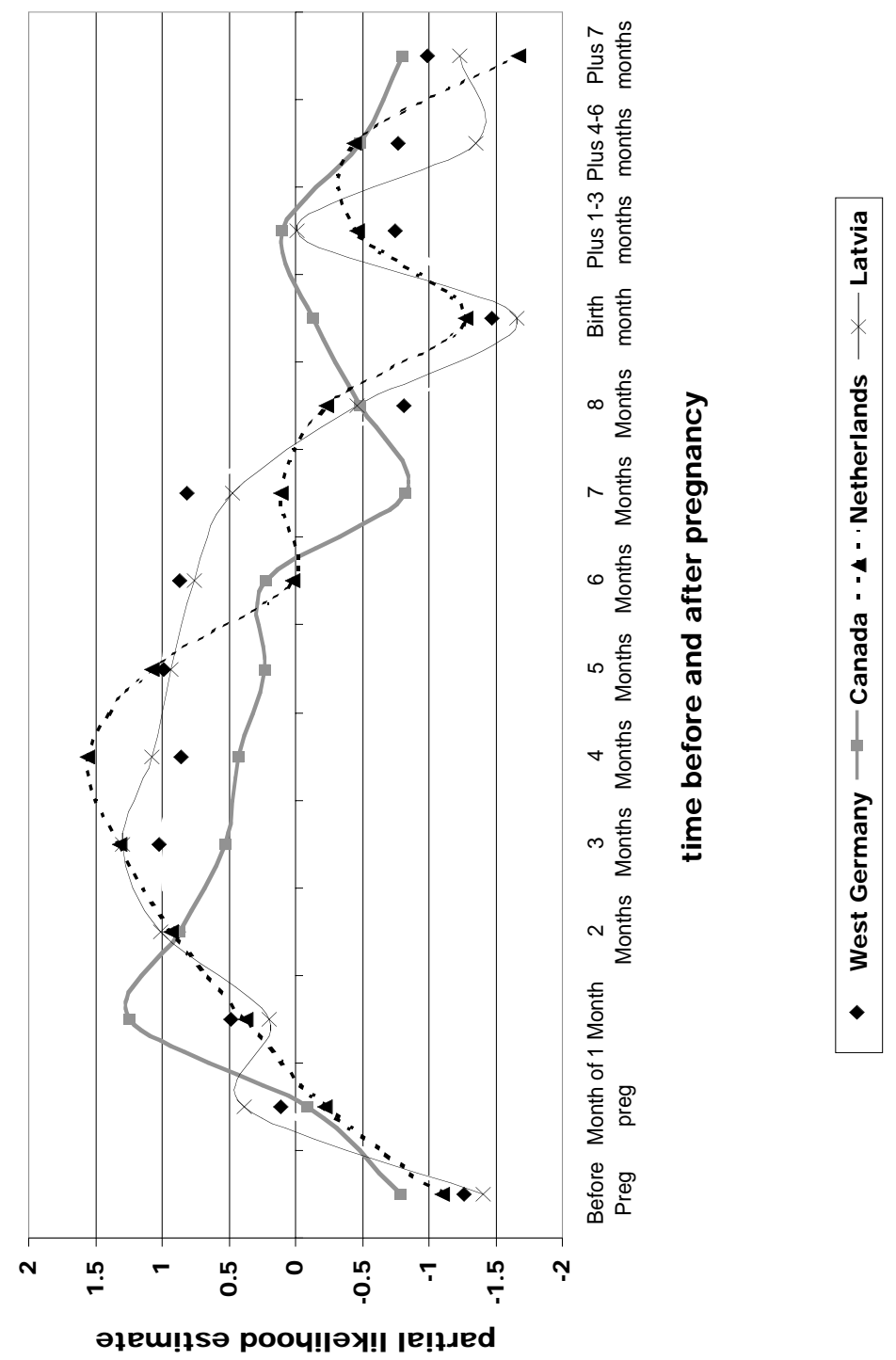


Empirical Research and Applications - Hans-Peter Blossfeld and Melinda Mills

\section{Substantive Explanations}

We previously speculated about these time-dependent effects in statistical terms, which does not, however, explain why we should expect a time-dependent fertility effect in substantive terms at all. Thus, how can the time-dependence in the fertility effect that we have found across a variety of countries be explained? Before we give a more detailed answer to this question, some more general remarks about actors and probabilistic causal relations in demography are in order (see Blossfeld and Rohwer, 1995).

\section{Actors, Probabilistic Causal Relations and the Hazard Rate}

There is a general consensus that demographic phenomena are always directly or indirectly based on actions of individuals. Demography therefore does not deal with associations among variables (e.g. pregnancy/birth and marriage) per se, but with variables that are associated via acting people (see Blossfeld and Prein, 1998). There are at least three consequences of explaining causal relations in demographic applications. First, if individuals relate causes and effects through their actions, then explanations of demographic processes should be related to individuals. This is why life history data on individuals, and not aggregated longitudinal data, provide the most appropriate empirical evidence for hypotheses about demographic change. Only with these data can one trace the courses of action at the level of individuals over time. Second, it means that explanations of demographic processes requires: (1) a time-related specification of structural constraints that reduces the set of possible courses of action to a small subset of feasible actions; and, (2) a mechanism that singles out which of the feasible courses of action shall be realized (see Elster, 1979). Because this is done for individuals, this mechanism must rest on the beliefs, expectations, and motivations of the agents. Third, if individuals are doing the acting, then causal inference must also take into account the free will of individuals.

The above argument introduces an essential element of indeterminacy into causal inferences. Hence, in demography, we can only reasonably account for and model the generality but not the determinacy of behaviour. The aim of substantive (and statistical) models must therefore be to capture common elements in the behaviour of people, or patterns of action that recur in many cases (Goldthorpe, 1998; 2000). This theoretical model must not seek to explain the behaviour of single individuals, but the behaviour of aggregate entities such as groups. As Stinchcombe (1968) has shown, the behaviour of large aggregates can be reasonably well comprehended, even when the individual components of the aggregate are poorly understood. Given this macro-level focus, small idiosyncratic deviations from the postulated model are not damaging (Hedström, 1995). The consequence, however, is that in demographic applications, randomness has to enter as a defining characteristic of causal models. 
We can only hope to make sensible causal statements about how a given (or hypothesized) change in variable $\mathrm{Y}_{t}^{A}$ (e.g., pregnancy/birth) in the past affects the probability of a change in variable $\mathrm{Y}_{t^{\prime}}^{B}$ (e.g., marriage) in the future. Correspondingly, the basic causal relation becomes:

$$
\Delta \mathrm{Y}_{t}^{A} \rightarrow \Delta \operatorname{Pr}\left(\text { (১) } \mathrm{Y}_{t^{\prime}}^{B}\right) \quad \mathrm{t}<\mathrm{t}^{\prime}
$$

In other words, a change in the time-dependent covariate $\mathrm{Y}_{t}^{A}$ will change the probability that the dependent variable $\mathrm{Y}_{t^{\prime}}^{B}$ will change in the future $\left(\mathrm{t}<\mathrm{t}^{\prime}\right)$. In demography, this interpretation seems more appropriate than the traditional deterministic approach. The essential difference is not that our knowledge about causes is insufficient allowing only probabilistic statements, but that the causal effect to be explained is itself a probability. Thus, probability in this context is not just a technical term anymore, but is considered a theoretical one: it is the propensity of social agents to change their behaviour intentionally.

Using event history data and hazard rate models, the causal reasoning underlying our approach can therefore be restated in a somewhat more precise form as:

$$
\Delta \mathrm{Y}_{t}^{A} \rightarrow \Delta \mathrm{r}\left(\mathrm{t}^{\prime}\right) \quad \mathrm{t}<\mathrm{t}^{\prime}
$$

As a causal effect, the changes in covariates $\mathrm{Y}_{t}^{A}$ in the past may lead to changes in the transition rate $r\left(t^{\prime}\right)$ in the future (in our example, marriage), which in turn describes the propensity that the actors under study will change their course of action. This causal interpretation requires that we take very seriously the temporal order in which the structural constraints evolve and the actors with their beliefs and motivations.

With regard to the marriage decision, it seems important to distinguish two completely different situations at the time of the discovery of the pregnancy: (1) the preferences of the partners to marry are vague and diffuse; and, (2) the couples have already reached a decision to marry or not to marry in the case of child. 


\section{Diffuse Marriage Preferences and the Negotiation Process}

In modern societies, many couples' preferences towards marriage might be quite vague and diffuse at the beginning of the pregnancy, such that pregnancy initiates a process of preference formation and persuasion. Formation means that initially rather vague preferences with regard to marriage are formed, resulting in more clear-cut preferences in a step-wise negotiation process. Persuasion means that an individual is led by a sequence of short-term improvements into preferring marriage over non-marriage, even if he or she has initially vaguely preferred nonmarriage over marriage. In such cases the discovery of a pregnancy engenders a process of change in preferences. This process of preference formation and persuasion will be very time-structured. On the one hand, the opportunity to legalize the birth of the child tends to decrease with the duration of pregnancy. At the same time, the likelihood of possible medical complications (premature birth, health problems, etc.) connected with the pregnancy and the visibility of pregnancy to other people increases.

Hence, the optimal time for marriage, in the sense of the smallest risk of medical complications connected with the pregnancy and the visibility of the pregnancy to other people, is at a relatively early pregnancy phase. On the other hand, the optimum in the sense of a safe, well thought out decision based on a negotiation process between the partners, is often at a relatively later phase of the pregnancy. Thus, there is constant tension between these opposing forces in an attempt to optimize the marriage timing, a tension that may often but not necessarily be connected to a considerable shift in preferences with regard to marriage. Based on these contradictory forces on the marriage decision process, one would expect that the rate of entry into marriage after the discovery of pregnancy at first increases with the duration of pregnancy and then, after reaching some maximum, decreases again as the time of birth comes closer. Of course, shortly before and after the birth, one would expect a very low marriage rate. Finally, after the birth has already taken place out of wedlock, the decision of whether or not to marry has a different quality. The child is then already 'illegitimate', and the time pressure to marry has disappeared. Thus, one has to expect again a relative low marriage rate after some time since the birth of the child.

Table 2 and Figure 2 illustrate that after controlling for several important covariates, women do indeed seem to follow this pattern with respect to the rate of entry into marriage: the marriage rate is very low before pregnancy across all countries; it generally increases strongly up to about 5 months before birth, then falls deeply around the time of birth, and is finally at a relatively low level more than 7 months after the birth.

In sum, our interpretation of the time-dependence in Table 2 is derived from a theoretically supposed underlying negotiation process at the level of the cohabiting couples, leading to a formation and perhaps a change in initially still unstructured preferences for marriage. The time-dependent dummy-variables in 
A Causal Approach to Interrelated Family Events: A Cross-national Comparison of Cohabitation, Nonmarital Conception and Marriage

this model, therefore, served as proxies for a theoretically important process that is hard (or even impossible) to measure.

\section{Unobserved Marriage Decisions and the Observed Rate of Entry into Marriage}

Of course, one could also argue that many couples have already reached a decision to marry or not to marry in the case of a child at the time of the discovery of the pregnancy. Thus, couples are in fact extremely heterogeneous with regard to their baseline rate to enter into marriage when the pregnancy is observed. A hypothetical example for this situation is given in Figure 3. It demonstrates that if the consensual union population consists of two groups - one with a constantly low marriage rate and the other with an increasing rate as pregnancy progresses. This neglected heterogeneity will result in a bell-shaped marriage rate because when pregnancy progresses, the composition of the unmarried couples shifts towards couples being 'less' or 'not' ready for marriage which, at first, increases and then decreases the observed effect pattern. Thus, if we do not know whether the couples have already reached a decision to marry at the time of pregnancy, we are unable to say whether the effects of the dummy variables are proxies for the formation of couples' decisions during pregnancy or for the heterogeneity in decisions at the beginning of pregnancy. Obviously, in reality both interpretations may be valid. The important conclusion is, however, that the discovery of a pregnancy leads to a changing marriage rate for most couples. Thus, even though the cohort effect is decreasing, individuals in East and West Germany, the Netherlands, Latvia and Canada have tended to avoid illegitimate births and to legalize the union before a child is born.

\section{Abortion, Miscarriage and the Problem of Conditioning on Future Events}

Another methodological problem of our analyses is that we have not yet considered the possibility of abortion and miscarriage. Couples can avoid the birth of children by abortion (and therefore marriage), or they can marry but then the woman experiences a miscarriage. Both these situations present a problem for our causal analysis because we do not have any information about abortion and miscarriages and have, therefore, constructed the time-dependent dummy variables on the basis of successful births. In other words, there is the danger that we have committed one of the most serious methodological errors in causal analysis: we have conditioned past events on future events, reversing the temporal order of cause and effect. However, as long as such conditions are random and concern only a small proportion of couples, as is the case with miscarriages, this objection is obviously not very important. Only if specific couples sort themselves out by choice in greater numbers, as is probably the case with abortion, then we get biased estimates. In particular, we overestimate the size of the pregnancy/birth effect because we systematically underrepresent in 
Figure 3

The Bell-Shaped rate of marriage as a result of neglecting groups with different rates

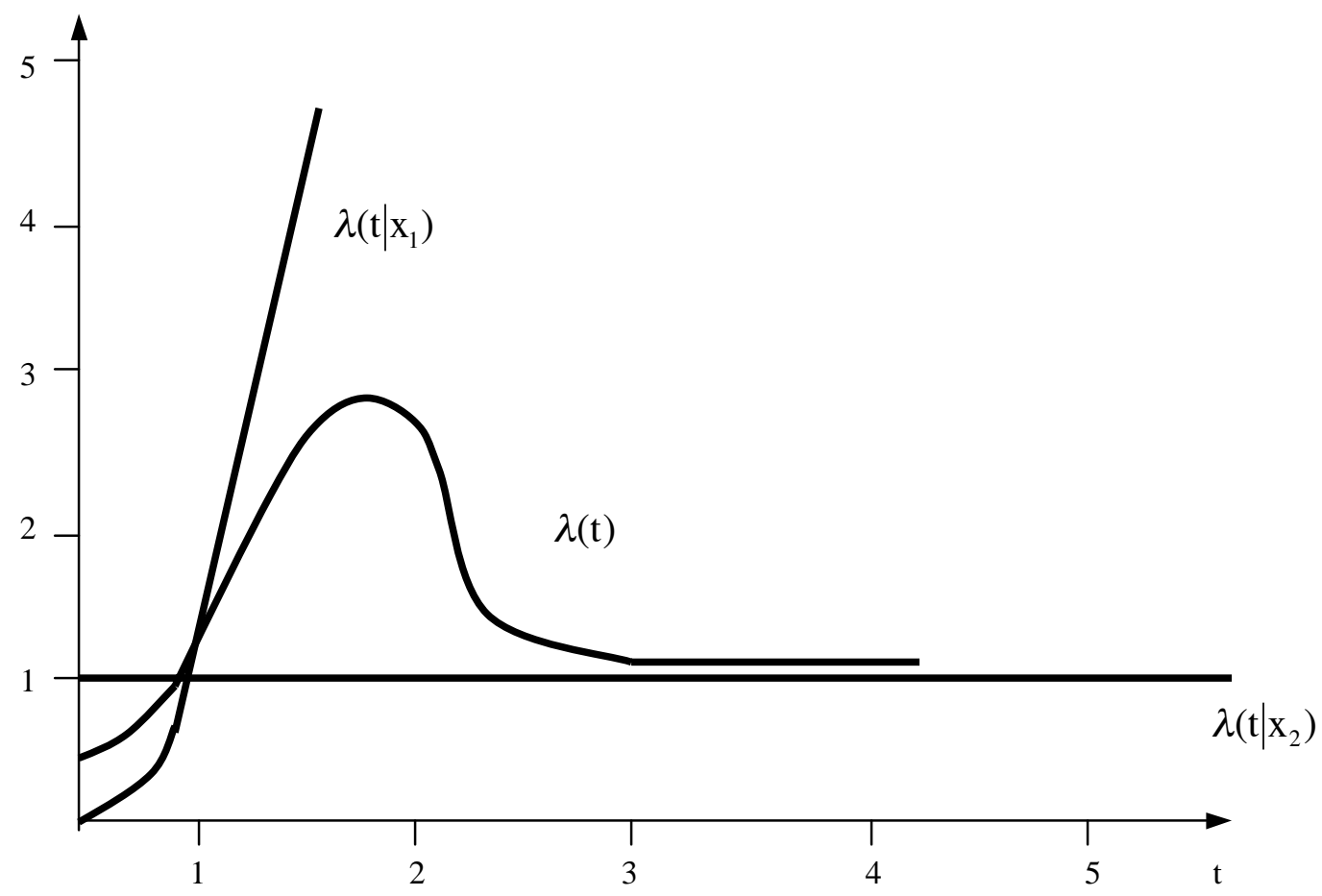


A Causal Approach to Interrelated Family Events: A Cross-national Comparison of Cohabitation, Nonmarital Conception and Marriage

our 'risk set of pregnant women' those women who would not have wanted to marry because of a child. That is, when we overestimate, the effect will be negative on the rate implying a downward bias. In the German Democratic Republic and Latvia, abortion was easier and more socially accepted than in the other countries. In Latvia, abortion is a widespread method of fertility control, with 111 terminated pregnancies per 100 live births and stillbirths in 1991 (Government of Latvia, 1999: 125).

Blossfeld et al. (1996) compared the significance of this downward bias based on a comparison of East and West Germany, finding that the pregnancy/birth effect is weaker at the beginning of the process and not significant. However, because in West Germany and the other countries discussed here abortion normally takes place during the first three months of a pregnancy, we can avoid the methodological problem by only interpreting the time-dependent dummy variables after the first three months of pregnancy. The analysis can then easily be redefined as one that only studies the effect of pregnancy/birth under the condition that the pregnancy was not interrupted during the first three months.

\section{Summary and Concluding Remarks}

The aim of this paper was to demonstrate the viability of the causal approach to interdependent systems using cross-national empirical investigations of interrelated family events of cohabitation, nonmarital conception, and marriage. The story these studies tell is persuasive. In substantive terms, the investigations confirm the existence of a highly time-dependent process between pregnancy and marriage for individuals in consensual unions across five different national contexts. But in particular, it shows that the force of an empirical analysis results from the clarity of the prior conceptual reasoning and the bringing together of seemingly contradictory evidence. All studies have been instructive in methodological terms because:

(1) they analyzed two highly interdependent processes from a causal point of view (the focus was on entry into first marriage as the dependent process and the events of first pregnancy/birth as the explaining one);

(2) the interdependence occurs mainly in a very specific phase of individuals' lives (i.e., during the period of first family formation);

(3) the relationship between cause and its effect involves time lags (e.g., time until detection of conception); and,

(4) the unfolding effect is highly dynamic over time (i.e., the effect of first pregnancy/birth on first marriage strongly depends on the progress of pregnancy and the time since the birth has taken place). 
In summary, these applications illustrate the substantive importance and methodological pitfalls of the identification of time-dependent causes and their time-dependent effect patterns.

Our central point is that we have been able to demonstrate that one process is influencing or causing a change in the other - even if they are interdependent. In cross-sectional data, we often have interdependent systems with feedback mechanisms, but we are unable to discern how one process influences the other. We witness associations, but cannot separate the effect. Statements about associations describe what has happened, but they are quite different from causal statements designed to say something about how events are produced or conditioned by other events. With the event history approach, however, it becomes possible to separate correlation and causation (Blossfeld and Rohwer, 1995).

Against these causal analytical studies, it is sometimes argued that since human actors act intentionally and behaviour is goal-oriented, actors' intentions or motives to bring about some effect in the future causes the actors to behave in a specific way in the present (Marini and Singer, 1988). This does not contradict our causal view. One simply has to distinguish intentions, motives or plans as they occur in the present from their impact on the behaviour that follows their formation temporally, and from the final result, as an outcome of the behaviour. An expectation about a future state of affairs should clearly be distinguished from what eventually happens in the future. Therefore, the fact that social agents can behave intentionally, based on expectations, does not reverse the time order underlying our causal statements.

Another problem, however, might arise when the analysis, as is the case here, is only based on observed behaviour. For example, it could happen that a couple first decide to marry, then, following this decision, the woman becomes pregnant, and finally the couple marry. In this case, we would observe pregnancy occurring before marriage and assume that pregnancy increases the likelihood of marriage. However, the time order between the processes is exactly the other way around; the couple decide to marry and then the woman gets pregnant. Since the time between decisions and behaviour is probably not random and is different for various couples, an analysis that uses only behavioural observations can lead to false conclusions. Courgeau and Lelièvre (1992) have introduced the notion of 'fuzzy time' for the time span between decisions and behaviour. Note, however, that this issue does not alter the key temporal issues embedded within the causal logic (see Blossfeld and Rohwer, 1995). There is clearly a time order with regard to decisions and behaviour. However, we must admit that only using the time order of behavioural events without taking into account the timing of decisions could lead to serious misspecification. Thus, for studies aiming to model the relationship between attitudes and behaviour over time, panel observations of attitudinal states, combined with retrospective information on behavioural events since the last wave, appear to be a very desirable design. 
A Causal Approach to Interrelated Family Events: A Cross-national Comparison of Cohabitation, Nonmarital Conception and Marriage

\section{End Notes:}

1. The basic model for the development of $\mathrm{Y}_{t}$ is a Markov model, which makes two assumptions. First, it assumes that the episodes defined with respect to $\mathrm{Y}_{t}$ are independent of previous history. If the past of the process makes the episodes dependent, it is crucial to include these dependencies as covariates in transition rate models at the beginning of each new episode of the $\mathrm{Y}_{t}$ process (Courgeau and Lelièvre, 1992). Second, the model assumes that the transitions to a destination state of the system are not allowed to depend on the episode's duration, but only on the type of states. However, as Rajulton (1992), Namboodiri (1991) and others have shown, the model could also be formulated as a semi-Markov one allowing for duration dependence in the various origin states.

2. Courgeau (1999, in discussion) recently attested that depending upon the specification, the two approaches can sometimes give similar results.

3. Following Blossfeld and Rohwer (1995), in the process of episode-splitting, a time-dependent covariate is used to 'split' the episodes. When at least one of the time-varying covariates changes its value, the original episode is 'split' into subepisodes. These sub-episodes contain information about the origin state of the original episode, starting values of the covariates at the beginning of the episode, starting and ending times of the subepisodes, and whether it ends with the specified destination state or is censored. The last subepisode has the same destination state as the original 'unsplit' episode. For a more detailed description of episode-splitting for the analyses shown in the application section, refer to Mills (2000: 98-102; 271-3).

4. We are viewing each of these two processes as having various states in their histories. For example, the partnership process could consist of the states of never married, consensual union, married and the pregnancy/birth process may consist of the states of not pregnant, pregnant and first child.

5. We would like to thank the Advisory Group of the FFS programme of comparative research for its permission, granted under identification number 7 , to use the FFS data on which this study was based.

6. The 1995 FFS data for Canada is derived from Statistics Canada's 1995 General Social Survey. The Canadian Fertility Survey may have also been useful for this analysis as it includes information on the timing of pregnancy, miscarriages, etc. in months and years. However, since it contains only the age at cohabitation in years and is much older (1984) than the other data files, it was not chosen for the analysis. 
Empirical Research and Applications - Hans-Peter Blossfeld and Melinda Mills

7. Since Statistics Canada does not release the month of event, but rather, the timing of events to each tenth of the year (i.e., age plus one decimal point), we developed a technique to translate these values to a 12 month scale which involved first estimating a random (uniform distribution) variable of age plus 3 decimal points, followed by a conversion scale to transform it into monthly data (for details see Mills and Trovato, forthcoming 2001). See also Mills (2000) for alternate estimates that vary slightly based on a different temporal assumption (i.e., whether events are randomly distributed or fixed at the middle of the year).

\section{References:}

Bernasco, W. 1994. Coupled Careers. The Effects of Spouse's Resources on Success at Work. Amsterdam: Thesis Publishers.

Blossfeld, H.-P. 1986. "Career opportunities in the Federal Republic of Germany: A dynamic approach to the study of life-course, cohort, and period effects," European Sociological Review 2: 208-225.

Blossfeld, H.-P. (ed.) 1995. Family Formation in Modern Societies and the New Role of Women. Boulder, CO: Westview Press.

Blossfeld, H.-P., A. Hamerle and K.U. Mayer. 1989. Event History Analysis. Hillsdale, NJ: Erlbaum.

Blossfeld, H.-P. and J. Huinink. 1991. "Human capital investments or norms of role transition? How women's schooling and career affect the process of family formation," American Journal of Sociology 97: 143-168.

Blossfeld, H.-P., D. Manting and G. Rohwer. 1993. "Patterns of change in family formation in the Federal Republic of Germany and the Netherlands: Some consequences for the solidarity between generations," in H.A. Becker and P.L.J. Hermkens (eds.). Solidarity of Generations. Demographic, Economic and Social Change, and its Consequences. Amsterdam: 175196.

Blossfeld, H.-P. and G. Rohwer. 1995. Techniques of Event History Modeling. New Approaches to Causal Analysis. Mahwah, NJ: Erlbaum.

Blossfeld, H.-P., E. Klijzing, K. Pohl, and G. Rohwer. 1996. "Die Modellierung interdependenter Prozesse in der demographischen Forschung: Konzepte, Methoden und Anwendung auf nichteheliche Lebensgemeinschaften," Zeitschrift für Bevölkerungswissenschaft 22: 29-56. 
A Causal Approach to Interrelated Family Events: A Cross-national Comparison of Cohabitation, Nonmarital Conception and Marriage

Blossfeld, H.-P. and C. Hakim (eds.). 1997. Between Equalization and Marginalization. Part-time Working Women in Europe and the United States of America. Oxford: Oxford University Press.

Blossfeld, H.-P. and G. Prein (eds.). 1998. Rational Choice Theory and Largescale Data Analysis. Boulder, CO: Westview Press.

Blossfeld, H.-P., E. Klijzing, K. Pohl, and G. Rohwer. 1999. "Why do cohabiting couples marry? An example of a causal event history approach to interdependent systems," Quality and Quantity 33(3): 229-42.

Blossfeld, H.-P. and S. Drobnič (eds.). Forthcoming. Careers of Couples in Contemporary Societies. Oxford: Oxford University Press.

Brien, M.J., Lillard, L.A. and L.J. Waite. 1999. "Interrelated family-building behaviors: Cohabitation, marriage and nonmarital conception," Demography 36: 535-551.

Courgeau, D. 1999. Discussion during session 'Demographic Analysis and Methodology' European Population Conference, The Hague, the Netherlands, August - September.

Courgeau, D. and E. Lelièvre. 1992. Event History Analysis in Demography. Oxford: Clarendon Press.

Easterlin, R. (1976) "The conflict between aspirations and resources," Population and Development Review 2(3): 417-425.

Eells, E. 1991. Probabilistic Causality. Cambridge: Cambridge University Press.

Elder, G.H. Jr. 1987. "Families and lives: Some developments in life-course studies," Journal of Family History 12(1-3): 179-199.

Elster, J. 1979. Ulysses and the Sirens. Cambridge: Cambridge University Press.

Freedman, R. A. 1991. "Statistical analysis and shoe leather," Sociological Methodology 21:291-313.

Gardner, W. and W.A. Griffin. 1986. "A structural-causal model for analyzing parallel streams of continuously recorded discrete events," University of Washington (mimeo).

Goldthorpe, J.H. 1998. "The quantitative analysis of large-scale data-sets and rational action theory: For a sociological alliance," in H.-P. Blossfeld and G. Prein (eds.) Rational Choice Theory and Large-scale Data Analysis. Boulder, CO: Westview Press: 31-53. 
Empirical Research and Applications - Hans-Peter Blossfeld and Melinda Mills

Goldthorpe, J.H. 2000. On Sociology. Oxford: Oxford University Press.

Government of Latvia. 1999. "National report submitted by the government of Latvia," Population in Europe and North America on the Eve of the Millennium. Geneva: United National Economic Commission for Europe: 123-9.

Hedström, P. 1995. "Rational choice and social structure: On rational-choice theorizing in sociology," in B. Wittrock (ed.) Social Theory and Human Agency. London: Sage.

Holland, P.W. 1986. "Statistics and causal inference," Journal of the American Statistical Association 81: 945-960.

Kalbfleisch, J. D. and R.L. Prentice. 1980. The Statistical Analysis of Failure Data. New York, NY: John Wiley and Sons.

Katus, K. 1992. "Fertility transition in Estonia, Latvia and Lithuania," in W. Lutz, Scherbov, and A. Volkov (eds.) Demographic Trends and Patterns in the Soviet Union Before 1991. London: Routledge: 89-111.

Kelly, J.R. and J.E. McGrath. 1988. On Time and Method. New Park, CA: Sage.

Lillard, L.A. 1993. "Simultaneous equations for hazards: Marriage duration and fertility timing," Journal of Econometrics 56: 189-217.

Lillard, L.A. and L.J. Waite. 1993. "A joint model of marital childbearing and marital disruption," Demography 30: 653-681.

Lillard, L.A., Brien, M.J. and L.J. Waite. 1995. "Premarital cohabitation and subsequent marital dissolution: A matter of self-selection?" Demography 32: $437-457$.

Manting, D. 1994. Dynamics in Marriage and Cohabitation. An Inter-temporal, Life Course Analysis of First Union Formation and Dissolution. Amsterdam: Thesis Publishers.

Marini, M.M. and B. Singer. 1988. "Causality in the social sciences," in C.C. Clogg (ed.) Sociological Methodology: 347-409.

Mayer, K.U. and J. Huinink. 1990. "Age, period, and cohort in the study of the life course: A comparison of classical A-P-C-analysis with event history analysis or farewell to Lexis?," in D. Magnusason and L.R. Bergmann (eds.) Data Quality in Longitudinal Research. Cambridge: Cambridge University Press: 211-232. 
A Causal Approach to Interrelated Family Events: A Cross-national Comparison of Cohabitation, Nonmarital Conception and Marriage

Mills, M. 2000. The Transformation of Partnerships. Canada, the Netherlands and the Russian Federation in the Age of Modernity. Amsterdam: Thela Thesis Population Studies Series.

Mills, M. and F. Trovato. Forthcoming 2001. "Shotgun weddings in Canada, the Netherlands, and Latvia: A causal event history approach to interdependent processes," United Nations Economic Commission for Europe's Statistical Journal 18(1)

Mills, M. and F. Willekens. 2000. Coping with exposure. Risk indicators in life history analysis. Paper presented at the joint conference of the British Society for Population Studies and the Nederlandse Vereniging voor Demografie, Utrecht, September.

Namboodiri, K. 1991. Demographic Analysis. A Stochastic Approach. San Diego, CA: Academic Press.

Pohl, K. 1995. "Kinderwunsch und Familienbildung in Ost- und Westdeutschland," Zeitschrift für Bevökerungswissenschaft 20: 67-100.

Pötter, U. and H.-P. Blossfeld. Forthcoming. "Causal inference from series of events," European Sociological Review

Rajulton, F. 1992. Life History Analysis. Guidelines for using the program LIFEHIST. Discussion Paper 92-5, Population Studies Centre, University of Western Ontario, Canada.

Stinchcombe, A.L. 1968. Constructing Social Theories. New York, NY: Harcourt, Brace, and World.

Tuma, N.B. and M.T. Hannan. 1984. Social Dynamics. Models and Methods. Orlando, FL: Academic Press.

Willekens, F.J. 1991. "Understanding the interdependence between parallel careers," in J.J. Siegers, J. de Jong-Gierveld and E. van Imoff (eds.) Female Labour Market Behaviour and Fertility: A Rational-Choice Approach. New York/Berlin: Springer-Verlag:11-31.

Yamaguchi, K. 1991. Event History Analysis. Newbury Park, CA: Sage.

Young, M.L. 1992. “Analyzing Household Histories,” in E. Berquó and P. Xenos (eds.) Family Systems and Cultural Change. Oxford: Clarendon Press: 176-200. 